\title{
CORRIGENDUM
}

\section{Offering prenatal diagnostic tests: European guidelines for clinical practice}

Heather Skirton, Lesley Goldsmith, Leigh Jackson, Celine Lewis and Lyn Chitty

European Journal of Human Genetics (2014) 22, 714; doi:10.1038/ejhg.2014.55

European Journal of Human Genetics (2014) 22, 580-586; doi:10.1038/

ejhg.2013.205; published online 11 September 2013

Since the publication of the above paper, there has been a minor change to the title. The journal would also like to clarify that this is a policy paper and extend thanks to the European Society of Human Genetics for their support. 